\title{
RETRACTED ARTICLE: Characterization and Evaluation of Mango Germplasm Through Morphological, Biochemical, and Molecular Markers Focusing on Fruit Production: An Overview
}

\author{
Riaz Ahmad ${ }^{1}$ - Muhammad Akbar Anjum ${ }^{1}$. Waqas Malik ${ }^{2}$
}

Published online: 12 October 2018

○) Springer Science+Business Media, LLC, part of Springer Nature 2018

The Editor-in-Chief has retracted this article [1]. An investigation by Bahauddin Zakariya University has not been able to establish what the appropriate authorship should be. As the appropriate authorship cannot be determined the Editor-in-Chief no longer has confidence in this article. Waqas Malik and Muhammad Akbar Anjum have each stated that they are not an author of this article. Riaz Ahmad agrees with this retraction.

1. Ahmad, R., Anjum, M.A. \& Malik, W. Mol Biotechnol (2018). https://doi.org/10.1007/s12033-018-0129-9.

Electronic supplementary material The online version of this article (https://doi.org/10.1007/s12033-018-0129-9) contains supplementary material, which is available to authorized users.

Muhammad Akbar Anjum

akbaranjum@bzu.edu.pk

Riaz Ahmad

riazahmadbzu@gmail.com

Waqas Malik

waqasmalik@bzu.edu.pk

1 Department of Horticulture, Bahauddin Zakariya University, Multan 60800, Pakistan

2 Genomics Lab, Department of Plant Breeding \& Genetics, Bahauddin Zakariya University, Multan 60800, Pakistan 